\section{EMBRYRIDDLE \\ Aeronautical University}

SCHOLARLY COMMONS
International Journal of Aviation, Aeronautics, and Aerospace

\title{
Analysis of Part 135 Aircraft Accidents to Facilitate Flight Data Monitoring
}

Chenyu Huang

University of Nebraska at Omaha, chenyuhuang@unomaha.edu

Follow this and additional works at: https://commons.erau.edu/ijaaa

Part of the Aviation Safety and Security Commons, and the Management and Operations Commons

\section{Scholarly Commons Citation}

Huang, C. (2020). Analysis of Part 135 Aircraft Accidents to Facilitate Flight Data Monitoring. International Journal of Aviation, Aeronautics, and Aerospace, 7(1). https://doi.org/10.15394/ijaaa.2020.1450

This Article is brought to you for free and open access by the Journals at Scholarly Commons. It has been accepted for inclusion in International Journal of Aviation, Aeronautics, and Aerospace by an authorized administrator of Scholarly Commons. For more information, please contact commons@erau.edu. 
Air services under Title 14 Code of Federal Regulations (CFR) Part 135 play a critical role in air transportation by offering scheduled commuter and ondemand operations such as air taxi, air medical, air tour, and cargo transportation (14 C.F.R. $\S 135.1,2019$ ). Air carriers operating with a Part 135 certificate vary from small single aircraft operators to large operators that provide a network to move passengers and cargo to a wide variety of destinations including larger Part 121 air carriers or remote areas. By December 2, 2019, there were 1,930 active operators approved for Part 135 operations with 11,209 total aircraft authorized on Part 135 certificates (Federal Aviation Administration [FAA], 2019c). Approximately $73 \%$ of the aircraft were fixed-wing airplanes and $27 \%$ t were rotorcraft. While various types of aircraft are operating in Part 135 services, the most frequently used type of aircraft is fixed-wing turbo jet with over one million annual flight hours in recent years (FAA, 2019b). Most on-demand Part 135 aircraft are equipped with navigation and communication equipment. Many highperformance fixed-wing airplanes are also equipped with sophisticated avionics such as the Ground Proximity Warning System (GPWS), Traffic Collision Avoidance System (TCAS), and weather equipment. With more advanced aircraft equipage installed after the year of 2000, Part 135 operations enjoyed a great decline of accident rate based on the aircraft accident statistics of the National Transportation Safety Board (NTSB) (NTSB, 2019a). However, the accident rate of Part 135 has the greatest variation with a high incident rate compared to Part 91 and Part 121 operations. Flight safety improvement for Part 135 operations features on the NTSB Most Wanted List for 2019-2020 (NTSB, 2019b). In comparison with Part 121 operations, the less stringent requirement of safety program criteria for Part 135 operations is expected to be one of the fundamental reasons for safety issues in Part 135 operations. Adopting more effective risk mitigation strategies is expected to be beneficial for further improving Part 135 flight safety. Implementation of Flight Data Monitoring (FDM) programs is suggested by the NTSB as one of the three safety recommendations for Part 135 operators, together with implementation of a Safety Management System (SMS) and a Controlled Flight into Terrain (CFIT) avoidance training program (NTSB, 2019b).

\section{Flight Data Monitoring}

Flight data monitoring (FDM), also known as Flight Operational Quality Assurance (FOQA) in the U.S., is "a voluntary program for the routine collection and analysis of flight operational data to provide more information about, and greater insight into, the total flight operations environment" (FAA, 2004, p. 1). The FDM program attempts to identify and mitigate critical risk events by routinely analyzing flight operational data before they manifest in aircraft incidents or accidents, shown as Figure 1. Routine flight data analysis consists of three primary components: onboard flight operational parameters recording systems, Ground 
Data Replay and Analysis System (GDRAS), and air/ground data transfers (FAA, 2004). Given the availability of modern Quick Access Recorder (QAR), over 1,000 flight parameters could be collected across a variety of aircraft systems, such as flight profile parameters, engine systems, fuel systems, and avionics systems (Campbell, 2007). The GDRAS is a generic name for flight data analysis software. Flight data analysts apply the GDRAS to analyze and report usable information to safety managers to proactively respond the anomalies during flight operations. Flight data analysis is primarily executed in the forms of flight operation exceedance detection and statistical trend of flight safety, for example, deviations from Standard Operating Procedures (SOPs), fuel inefficiencies, system deficiencies, and Powerplant deterioration. The FDM program has been promoted as an effective strategy to detect unsafe occurrences and monitor overall safety status of flight operations by the International Civil Aviation Organization (ICAO) and many other local aviation agencies. In the U.S., the FOQA/FDM is encouraged as a voluntary program for Part 121 operators by the FAA, Part 135 operators are also highly encouraged to implement flight data monitoring by the NTSB (FAA, 2004; NTSB, 2019b). However, the high cost of FDM programs discourages many Part 121 operators from implementation, not to mention the resource constrained Part 135. Figure 2 shows the current implementation of FDM/FOQA programs in Part 121 and Part 135 operations in the U.S (FAA, 2019a, 2020).

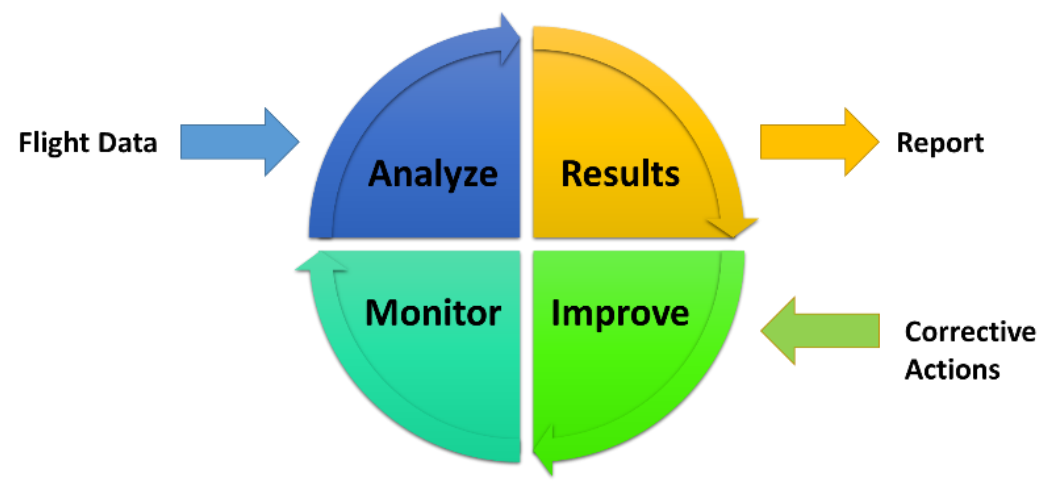

Figure 1. Procedure of routine flight data monitoring. 


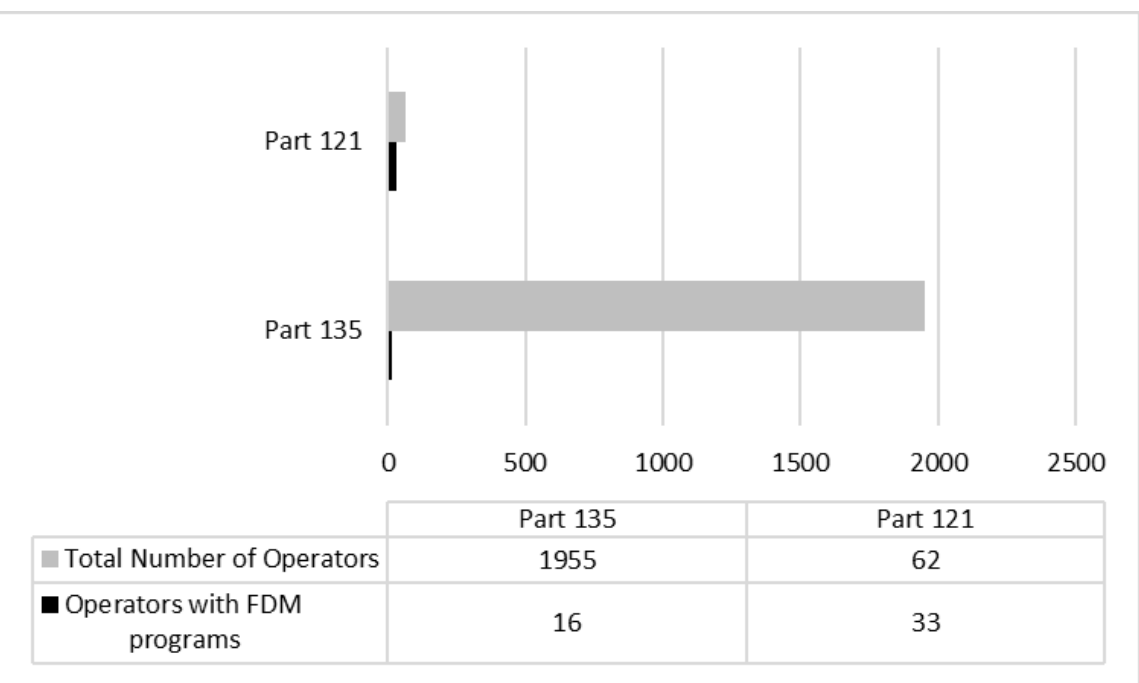

Figure 2. Implementation of FDM/FOQA programs in Part 135 and Part 121 operators (FAA, 2020; 2019a).

One of the most prominent factors that drives the high cost of FDM programs is the collection and analysis of large volume of flight data, to identify the critical elements of flight parameters is believed to be necessary for the development of more practical and effective FDM programs. In addition, Part 135 operators show different operational features from Part 121 operators because of different types of aircraft and services; compared to comprehensively monitoring all aircraft parameters and operational data, scientifically monitoring and analyzing critical categories of aircraft data may make the FDM programs less expensive and more practical for Part 135 operators. Currently limited studies on Part 135 operations impede the development and implementation of more practical and effective FDM programs.

\section{NTSB Aviation Accident Database \& Synopses}

The NTSB provides downloadable weekly updated datasets containing aircraft accident and incident information beginning from 1982 (NTSB, 2019a). The information is managed using Microsoft Access database with 22 tables of datasets. In addition to descriptive information of involved aircraft, flight crew, and environment, the datasets contain the findings of NTSB accident investigations, such as the sequence of events, occurrences, and causes. In the database, the NTSB accident investigation reports define accident causes into five main categories: aircraft issues, personnel issues, environmental issues, organizational issues, and not determined category. Aircraft issues refer to aircraft related faults, deficiency, or factors, personnel issues refer to human factors and errors, environmental issues include all environmental related causes, and the organizational issues include mistakes from the organizational level. In addition, sub-categories were defined 
under each of five category of accident causes. This study focused on aircraft issues related data provided the primary working principle of FDM programs is to monitor aircraft operational data.

\section{Literature Review Analysis of Accident using the NTSB Database}

Aircraft accident investigation collects and analyzes the available mishap data to determine the causes of accidents and make safety recommendations for the purpose of preventing future accidents (ICAO, 2016). In addition to the safety recommendations based on the findings of aircraft accident investigations, valuable data gathered in the process of accident investigations provide greater insights into aircraft accident prevention from a variety of aspects. Numerous published studies analyzed aircraft accident records from different perspectives. Li et al. examined the crash risk in general aviation (GA), correlates of pilot fatalities in general aviation crashes, and factors associated with pilot error in aviation crashes (Li \& Baker, 2007; Li \& Baker, 1999; Li, Baker, Grabowski, \& Rebok, 2001). Boyd et al. extensively studied the causes of aircraft accidents under different conditions by analyzing the NTSB aircraft accident database, such as the causes of fatal accidents for instrument-certified and non-certified private pilots, the causes of fatal accidents in non-commercial twin engine piston GA aircraft, the causes of accidents for GA aircraft operating in a mountainous and high elevation terrain environment, and accident causes of fatal GA accident in furtherance of business (Shao, Guindani, \& Boyd, 2014; Boyd, 2015; Aguiar, Stolzer, \& Boyd, 2017; Burgess, Boyd, \& Boyd, 2018). Bazargan et al. explored the factors contributing to fatalities in GA accidents using the NTSB aircraft accident data, such as gender, age, experience, and environmental conditions (Bazargan, \& Guzhva, 2011; 2010).

\section{Analysis of Part 135 Aircraft Accidents}

Above studies reported a variety of findings and recommendations on aircraft accident analysis and prevention primarily concentrated on Part 91 operations or overall GA. Nevertheless, publications from government and aviation organizations provide statistical information on Part 135 operation safety, such as the reports from the FAA 135 air carrier operation branch, general aviation and Part 135 activity surveys General Aviation Manufacturers Association (GAMA) annual reports, and the NTSB annual summary of U.S. civil aviation accidents. In addition, research publications were reviewed containing analytical studies of Part 135 accidents. For instance, Boyd and Macchiarella studied the occupant injury severity and accident causes in Part 135 helicopter emergency medical services, and suggested updating aircraft for instrument flight capability (Boyd \& Macchiarella, 2016). Rebok et al. reported pilot age was associated with crash circumstances but not with the prevalence and patterns of pilot error in air taxi crashes (Rebok, Qiang, Baker, \& Li, 2009). Khatwa and Roelen investigated the factors associated with 
Controlled Flight into Terrain (CFIT) accidents involving air taxi, regional and major carriers (Khatwa \& Roelen, 1997). However, not enough insights could be adopted to support better Part 135 flight data monitoring from the existing limited studies on Part 135 operations.

Given the limited studies on Part 135 aircraft accidents and the NTSB recommendation of implementing FDM programs, this study attempted to identify common aircraft issues from Part 135 aircraft accidents and analyzed the risk factors associated with aircraft issues. Understanding the characteristics of aircraft issues in Part 135 operations would benefit the development of more practical and scalable FDM programs to fit Part 135 operations. In this study, the historical accident investigation information published by the NTSB was leveraged to explore the critical aspects of aircraft issues that caused Part 135 aircraft accidents. The study results are expected to provide important insights into the common aircraft issues in Part 135 aircraft accidents, therefore, more practical and effective FDM programs could be developed and appropriately scaled to smaller and critical aspects of aircraft data in Part 135 operations.

\section{Data Collection}

\section{Methodology}

For this study, Part 135 aircraft accident information was retrieved from the NTSB Aviation Accident Database \& Synopses and Summary of U.S. Civil Aviation Accident updated on October 1st, 2019 (NTSB, 2019a). Aircraft accident records for operations under 14 CFR, Part 135 - Air Taxi \& Commuter, occurring between January 2008 and January 2019, were queried. Additional accident data for CFR Part 121 - Air Carriers and CFR Part 91 - General Aviation during the same time span were also collected for comparative analysis. Considering different flight characteristics due to the diverse categories of aircraft and purposes of flight, CFR Part 135 aircraft accidents were limited to airplane; helicopters and other type of aircraft were excluded in the data query. Microsoft Access database management system was used for data preparation and repository. In addition, available final accident investigation reports were retrieved to supplement causal and contributing factor information. Fatal outcome, causes, and contributing factors were determined per the NTSB reports (NTSB, 2019a). The total annual flight hours for Part 135 operations were obtained from the FAA survey to determine the accident rate (FAA, 2019c). Given above criteria, 435 CFR Part 135 aircraft accidents comprised of 263 accidents caused by aircraft related issues and 172 accidents not caused by aircraft issues were collected for analysis. The categories of accident causes and risk factors used in analysis were identical to the NTSB aircraft accident database and investigation reports. 


\section{Study Approach}

With the purpose of exploring the insights for the development of more practical and effective flight data monitoring programs for Part 135 operators, this study focuses on analyzing common Part 135 aircraft issues that caused aircraft accidents, as well as the risk factors associated with such accidents. The following work was accomplished in this study:

1. General descriptive analysis was conducted to present the features of Part 135 aircraft issue caused accidents considering factors including the time of occurrence, phase of flight, type of aircraft, flight crew, and weather condition.

2. The Chi-square linear-by-linear association was employed for trend assessment of Part 135 aircraft issue caused accidents.

3. Lists of aircraft issues were identified as common causes for aircraft accidents.

4. Logistic regression analysis was employed to identify risk factors for Part 135 accidents caused by aircraft issues.

\section{Results \\ Descriptive Analysis of Part 135 Aircraft Accidents}

In total, 263 Part 135 aircraft accidents involved with aircraft issues were identified through 2008 to 2018. Basic descriptive analysis of Part 135 aircraft issue related accidents with different risk factors provides important and straightforward information of the statistical features of accidents. By reviewing relevant literature, the following potential risk factors were selected from available data: the time of occurrence, phase of flight, type of aircraft, flight crew, and weather condition.

Given the unavailability of Part 135 aircraft movement or hours flown per season, the percentage of aircraft issue related accident over the total number of Part 135 aircraft accident per season was used to reflect the seasonal characteristics of aircraft issue related accidents, shown as Figure 3. Through 2008 to 2018, higher percentages of Part 135 aircraft issue caused accidents happened in winter and summer while spring and fall show relatively lower percentages. Meanwhile, the distribution of Part 135 aircraft issue caused accidents per weather condition and light condition across the same period of study is shown in Table 1. Most such type of accidents happened in visual meteorological condition (VMC) with good light condition, few accidents happened in instrument meteorological condition (IMC) at dusk. 


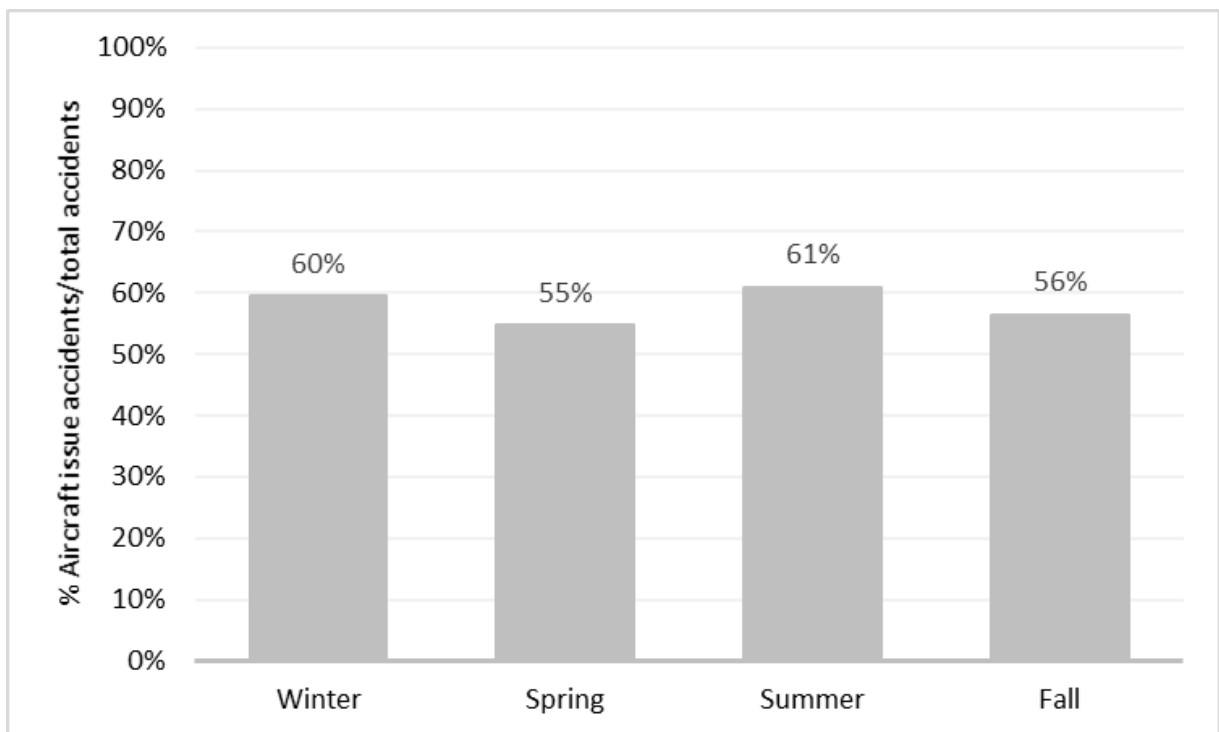

Figure 3. Part 135 aircraft issue related accidents per season of the year through 2008 to 2018.

Table 1

Part 135 Aircraft Issue Related Accident Distribution per Weather and Light Condition 2008 to 2018

\begin{tabular}{llll}
\hline & Dark & Light & Dusk \\
\hline IMC & 25 & 30 & 2 \\
\hline VMC & 49 & 224 & 13 \\
\hline
\end{tabular}

From the perspective of phase of flight and type of aircraft, the collected accidents are distributed as Figures 4 and 5, respectively. Findings from this study are in line with the reports of overall Part 135 aircraft accident characteristics from other aviation agencies, such as the FAA's Study of Operators Regulated under Part 135, the approach/landing phase of flight is accountable for most accidents followed by the takeoff/initial climb phase of flight; single piston engine and twin piston engine aircraft share most Part 135 aircraft issue caused accidents (FAA, 2016). Therefore, the approach/landing and takeoff/initial climb phases of flight might be given more attention while developing FDM programs, meanwhile, single and twin piston engine aircraft under Part 135 should be more targeted by flight data analysts and safety managers. 


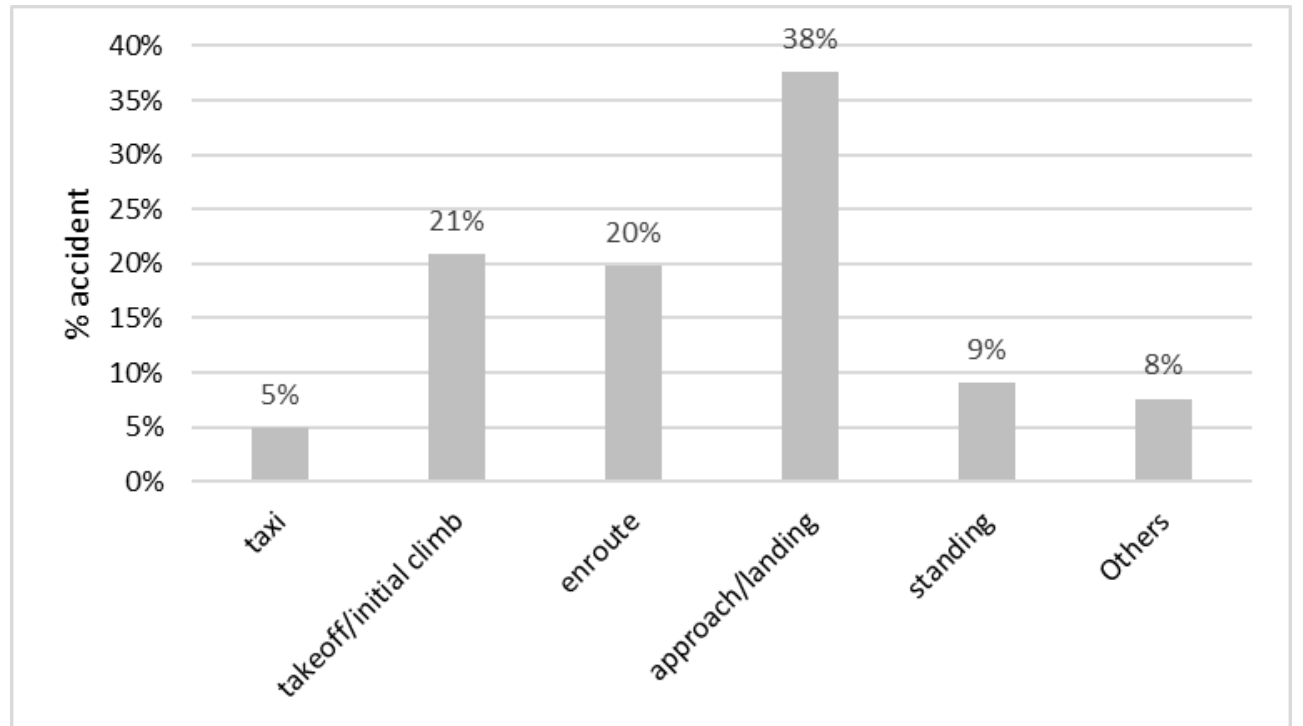

Figure 4. Part 135 aircraft issue related accident distribution per phase of flight.

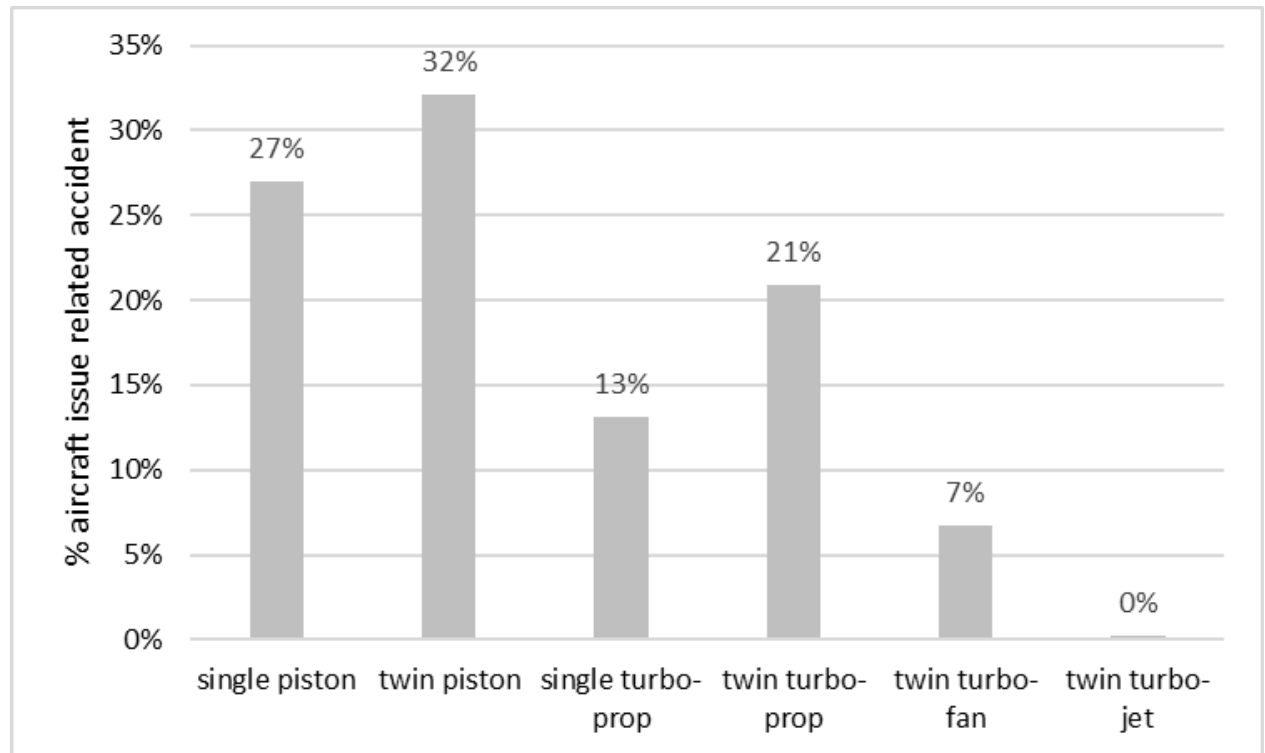

Figure 5. Part 135 aircraft issue related accident distribution per type of aircraft.

In terms of the influence from flight crew on aircraft issue caused accidents, pilot age and flight experience in collected Part 135 accidents are summarized in Table 2. Pilots involved in aircraft issue caused accidents were likely experienced pilots according to their age, total flight hours, hours flown on the same aircraft 
model. Further analysis of pilot related factors is presented in the section of Risk Factors for Part 135 Aircraft Issue Related Accidents.

Table 2

Pilot Age and Experience in Part 135 Aircraft Issue related Accidents

\begin{tabular}{lllll}
\hline & Maximum & Minimum & Mean & Median \\
\hline Pilot age & 77 & 20 & 46 & 46 \\
\hline $\begin{array}{l}\text { Total flight } \\
\text { hours }\end{array}$ & 30067 & 410 & 7587 & 5286 \\
\hline $\begin{array}{l}\text { Fight hours } \\
\text { on the same } \\
\text { aircraft } \\
\text { model }\end{array}$ & 20000 & 11 & 1833 & 718 \\
\hline
\end{tabular}

\section{Temporal Trend of Part 135 Aircraft Issue Caused Accidents}

The number of aircraft departures and the number of passenger departures are usually two effective denominators for aircraft accident rate, and the number of accidents per hours flown is often used to estimate aircraft accident rate when the number of aircraft departures or passenger departures is not available. Aircraft accident rate and statistics are published by the NTSB and the FAA annually. However, the statistics of the causes of aircraft accidents are limited, little information about the significance of aircraft issue in aircraft accidents is summarized and analyzed in the NTSB or FAA reports. This study presents the statistics of aircraft issue caused accidents across the studied timespan, shown as Figure 6. Over 11 years, Part 135 operations show the highest percentage of accidents that were caused by aircraft issues compared to Part 91 and Part 121 operations, Part 121 aircraft indicate the lowest percentage of accidents involved with aircraft issues. 


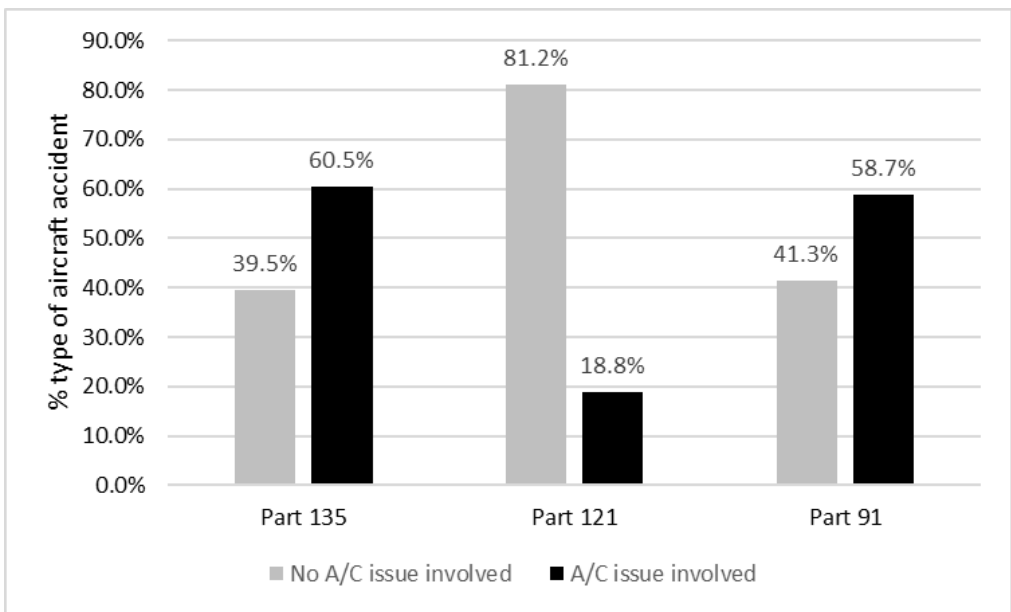

Figure 6. Percentages of aircraft issue caused accidents through January 2000 to January 2019.

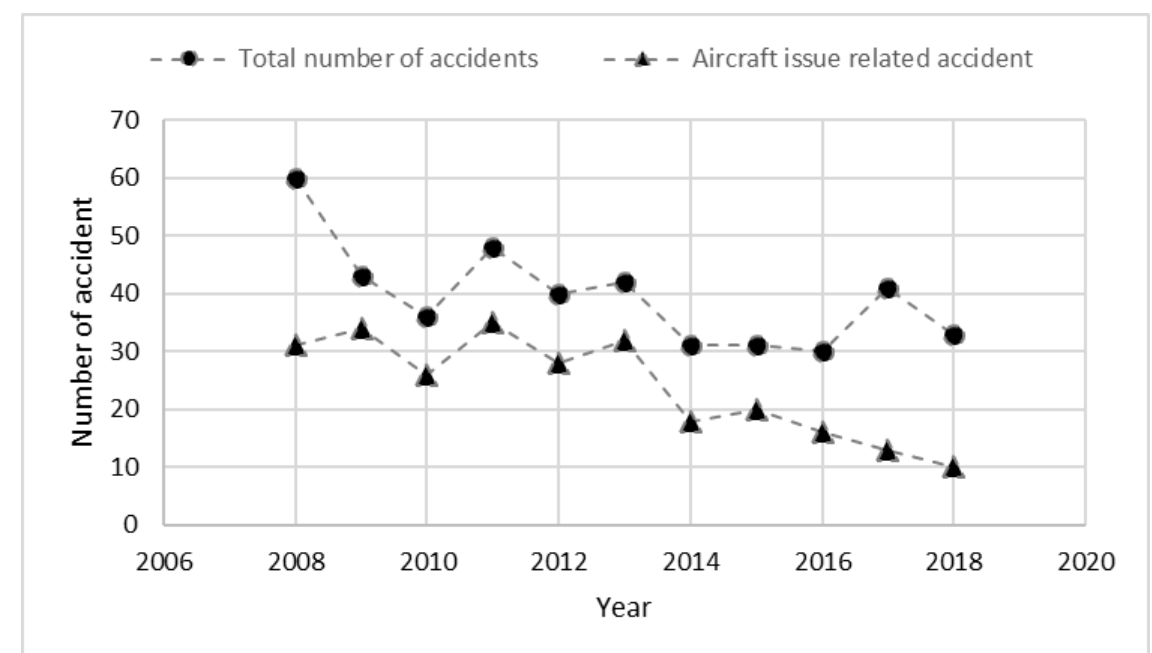

Figure 7. Total Part 135 aircraft accidents and Part 135 aircraft issue caused accidents through 2008 to 2018.

Further exploration of the NTSB aviation accident statistics by the time of year shows that Part 135 aircraft issue caused accidents count a big portion of total number of accidents. As shown in Figure 7, through 2009 and 2013, over 70\% of Part 135 aircraft accidents involved aircraft issues in the U.S., and the ratio of aircraft issue caused accidents to the total number of accidents reached to a low level in 2008 and 2018. Analysis of the temporal trend of accident was widely used to provide a better understanding of this particular type of aircraft accident (Agresti, 2012; Boyd, 2015). In this study, the test of temporal trends of Part 135 aircraft 
issue caused accident proportions across the studied timespan was based on the Chisquare linear-by-linear association. In addition, Chi-square test was also used to determine if a difference in aircraft issue caused accidents comparing the initial time of 2008 and a subsequent period was statistically significant. The ratios of Part 135 aircraft issue caused accidents over the total number of Part 135 aircraft accidents for the corresponding time period are shown in Figure 8. The $p$-values indicate the statistical level relative to the aircraft issue caused accident ratio in 2008. The Chi-square linear-by-linear association shows a significant result ( $p$ value $<0.001)$, therefore, there was a statistical association between the studied years and the ratio of aircraft issue caused accidents. The $p$-values of Chi-square tests at $5 \%$ of significance level, in the comparison between 2008 and the following years, shows a statistically significant increase in the years of 2009, 2011, 2013 and marginally significant decrease in the years of 2017 and 2018.

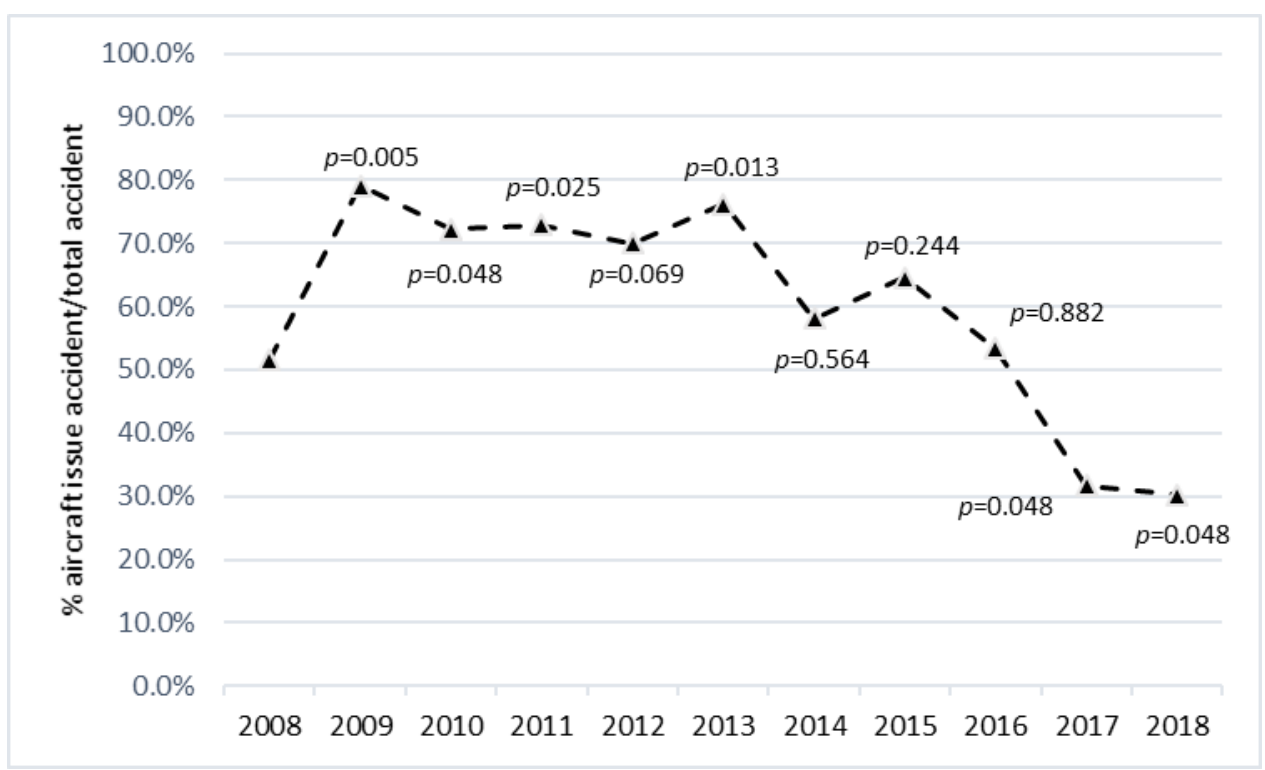

Figure 8. Temporal analysis of Part 135 aircraft issue caused accident percentage. $P$-values indicate the statistical level relative to the corresponding accident ratio in 2008.

\section{Common Aircraft Issues in Part 135 Accidents}

The NTSB accident investigation reports define accident causes into five main categories: aircraft issues, personnel issues, environmental issues, organizational issues, and not determined category. In addition, sub-categories were defined under each of five category of accident causes. Under the aircraft issues, seven sub-categories are defined: fluid/miscellaneous hardware, aircraft 
systems, aircraft structures, aircraft power plant, aircraft operation/performance/capability, aircraft handling, and aircraft propeller/rotor. According to the NTSB definition, the most common aircraft issues in Part 135 aircraft accidents are identified based on the frequency cited in the NTSB aircraft accident reports for the studied period, shown as Table 3. Frequency represents the frequency of such aircraft issue cited in the NTSB accident reports as the probable cause for accident. Frequency of sub-category represents the frequency of subcategorical aircraft issues cited in the NTSB accident reports.

Table 3

Common Aircraft Issues in Part 135 Aircraft Accidents

\begin{tabular}{|c|c|c|c|}
\hline Category & Frequency & $\begin{array}{l}\text { Sub- } \\
\text { category }\end{array}$ & $\begin{array}{l}\text { Frequency of } \\
\text { sub-category }\end{array}$ \\
\hline \multirow[b]{2}{*}{$\begin{array}{l}\text { Fluids/miscellaneous } \\
\text { hardware }\end{array}$} & \multirow[b]{2}{*}{$6.5 \%$} & Fluid level & $1.8 \%$ \\
\hline & & $\begin{array}{l}\text { Fuel and fluid } \\
\text { management }\end{array}$ & $1.4 \%$ \\
\hline \multirow{3}{*}{ Aircraft systems } & \multirow{3}{*}{$21.1 \%$} & $\begin{array}{l}\text { Landing gear } \\
\text { failure }\end{array}$ & $13.6 \%$ \\
\hline & & Hydraulic failure & $2.2 \%$ \\
\hline & & $\begin{array}{l}\text { Electrical power } \\
\text { system failure }\end{array}$ & $1.8 \%$ \\
\hline Aircraft Structure* & $3.6 \%$ & None & None \\
\hline \multirow[t]{2}{*}{ Aircraft power plant } & \multirow[t]{2}{*}{$15.5 \%$} & $\begin{array}{l}\text { Reciprocating } \\
\text { engine power } \\
\text { section failure }\end{array}$ & $8.6 \%$ \\
\hline & & $\begin{array}{l}\text { Turbine section } \\
\text { failure }\end{array}$ & $3.6 \%$ \\
\hline \multirow{4}{*}{$\begin{array}{l}\text { Aircraft operation } \\
\text { capability } \\
\text { exceedance }\end{array}$} & \multirow{4}{*}{$51.1 \%$} & $\begin{array}{l}\text { Directional control } \\
\text { not } \\
\text { attained/maintained }\end{array}$ & $14.8 \%$ \\
\hline & & $\begin{array}{l}\text { Glide path not } \\
\text { attained/maintained }\end{array}$ & $5.4 \%$ \\
\hline & & $\begin{array}{l}\text { Altitude not } \\
\text { attained/maintained }\end{array}$ & $5.1 \%$ \\
\hline & & $\begin{array}{l}\text { Airspeed not } \\
\text { attained/maintained }\end{array}$ & $6.1 \%$ \\
\hline Aircraft handling* & $1.8 \%$ & None & None \\
\hline $\begin{array}{l}\text { Aircraft } \\
\text { propeller/rotor* }\end{array}$ & $0 \%$ & None & None \\
\hline
\end{tabular}

Note. *represents that such category does not contain common sub-categorical aircraft issues as accident causes. Only the values of common aircraft issues are included in Frequency and Frequency of sub-category respectively, thus the sum of values does not equal "1" in the table. 
According to above statistics of identified common aircraft issues resulted in Part 135 aircraft accidents, the common aircraft issues could be expressed in Figure 9 (a) and (b). Aircraft operation capability exceedance was accountable for over 50 percent of aircraft issues in Part 135 aircraft accidents as the most common categorical aircraft issue followed by aircraft systems and aircraft power plant. Directional control not attained/maintained, landing gear failures, and reciprocating engine section failures counted over 55 percent of aircraft sub-categorical issues. The findings of common Part 135 aircraft issues in accidents are expected to help the development of FDM program better scope the critical flight parameters that should be monitored.

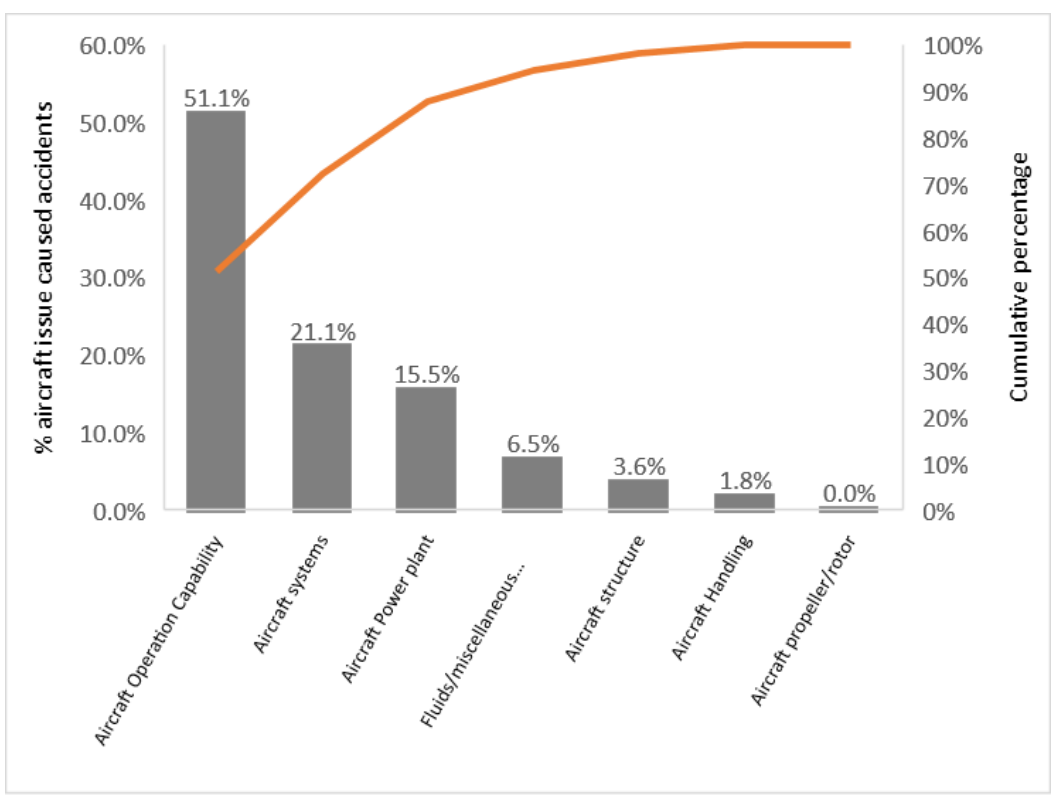

(a) 


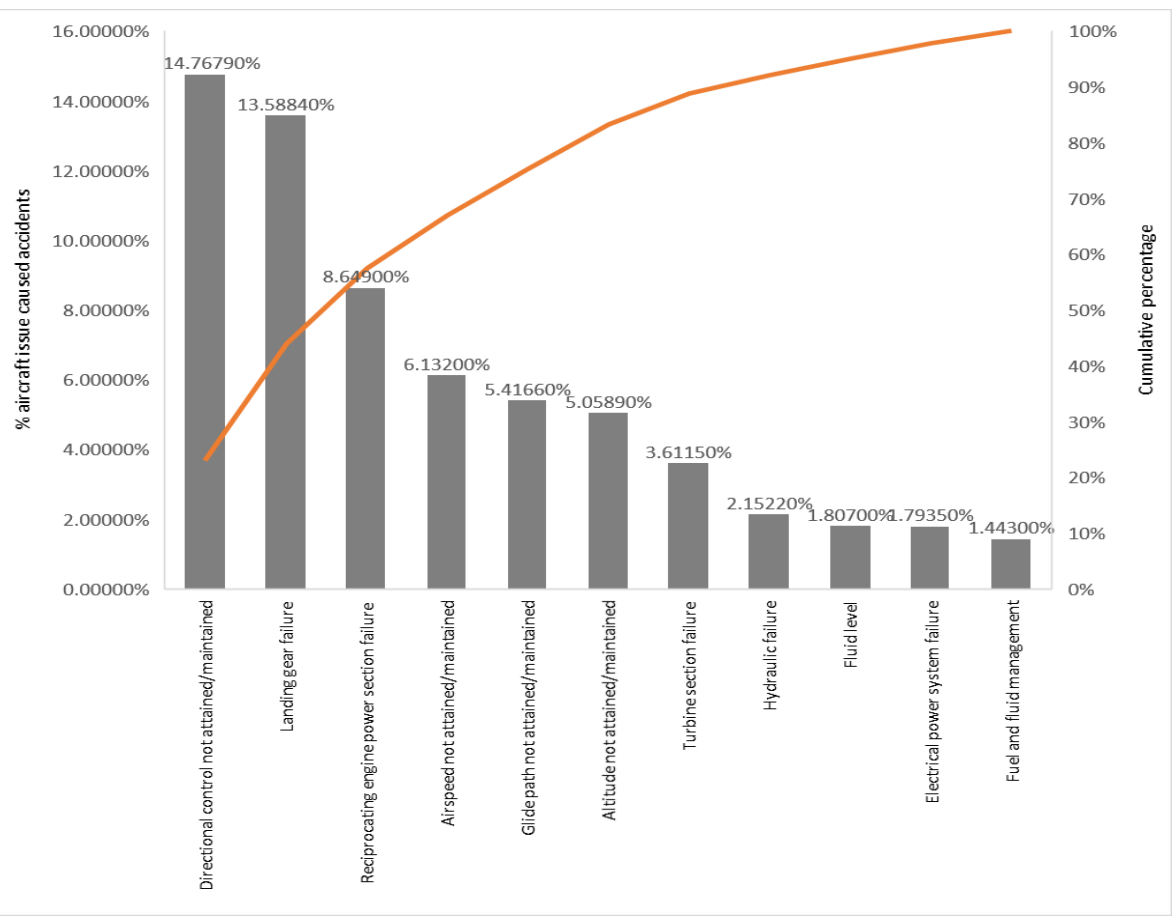

(b)

Figure 9. The common aircraft issues in Part 135 aircraft accidents through 2008 to 2018. (a) Main categorical aircraft issues, (b) sub-categorical aircraft issues.

\section{Risk Factors for Part 135 Aircraft Issue Caused Accidents}

An aircraft accident is usually the result of a chain of events influenced by many factors (Reason, 1990). A good understanding of risk factors that may contribute to aircraft mishaps is expected to provide safety manager insights of risky flight operational situations that additional caution should be given. According to the distribution of common aircraft issues in Part 135 aircraft accidents (Figures 8, 9, and Table 1) and findings from the literature review, flight experience (Li \& Baker, 1999; Rebok, Qiang, Baker, McCarthy, \& Li, 2005; Bazargan \& Guzhva, 2007), pilot age (Rebok, Qiang, Baker, McCarthy, \& Li, 2005; Bazargan \& Guzhva, 2007), pilot certificate (Groff \& Price, 2006), instrument rating (Bazargan \& Guzhva, 2007; Boyd, 2015), weather and light condition (Khatwa \& Roelen, 1997; Li \& Baker, 1999; Groff \& Price, 2006; Bazargan \& Guzhva, 2007; Boyd, 2015), number of engines (Bazargan \& Guzhva, 2007), type of engine, maximum gross weight (Bazargan \& Guzhva, 2007), airframe hours, fuel system, and season of the year were selected as potential risk factors for modeling.

Logistic regression is robust to the violation of the normality assumption and unequal variance within independent variable groups (Tabachnick \& Fidell, 
1996). this study adopted logistic regression analysis with $5 \%$ significance level to examine the influence from identified risk factors for Part 135 aircraft issue caused accidents. Table 4 presents selected variables with corresponding coding descriptions. The model is expressed as Equation (1).

\footnotetext{
Aircraft accident $_{i}=a_{1} \log ($ modelhours $)+a_{2} \log ($ totalhours $)+$ $a_{3}$ Certificate $_{i}+a_{4}$ Rating $_{i}+a_{5}$ Weather $_{i}+a_{6}$ EngineNum $_{i}+a_{7}$ EngineType $_{i}+$ $a_{8}$ Weight $_{i}+a_{9}$ AirframeHours $_{i}+a_{10}$ FuelMgt $_{i}+a_{12}$ Light $_{i}+a_{13}$ Season $_{i}+b+$ $e_{i}$ 
Table 4

Variables for Logistic Regression Analysis

\begin{tabular}{|c|c|c|}
\hline Variable & Coding & Description \\
\hline \multirow{2}{*}{ Type of Accident } & 0 & $\begin{array}{l}\text { Not aircraft issue related } \\
\text { accident }\end{array}$ \\
\hline & 1 & $\begin{array}{l}\text { Aircraft issue related } \\
\text { accident }\end{array}$ \\
\hline $\begin{array}{l}\text { Pilot Flight Experience by Hours } \\
\text { Flown with the Same Model }\end{array}$ & Log(modelhours) & Log transformation \\
\hline $\begin{array}{l}\text { Pilot Flight Experience by Total } \\
\text { Hours Flown }\end{array}$ & Log(totalhours) & Log transformation \\
\hline \multirow{3}{*}{ Pilot Certificate } & 0 & $\begin{array}{l}\text { Airline Transport Pilot } \\
\text { (ATP)/Commercial }\end{array}$ \\
\hline & 1 & $\begin{array}{l}\text { Certified Flight Instructor } \\
\text { (CFI)/Commercial }\end{array}$ \\
\hline & 2 & Commercial \\
\hline \multirow{2}{*}{ Instrument Rating } & 0 & No \\
\hline & 1 & Yes \\
\hline \multirow[b]{2}{*}{ Weather Condition } & 0 & $\begin{array}{l}\text { Visual Meteorological } \\
\text { Conditions (VMC) }\end{array}$ \\
\hline & 1 & $\begin{array}{l}\text { Instrumental } \\
\text { Meteorological Conditions } \\
\text { (IMC) }\end{array}$ \\
\hline \multirow{2}{*}{ Number of Engines } & 0 & Single engine \\
\hline & 1 & Twin engine \\
\hline \multirow{3}{*}{ Type of Engine } & 0 & Reciprocating \\
\hline & 1 & Turbo Prop \\
\hline & 2 & Turbo Fan \\
\hline Maximum Gross Weight & Log(weight) & Log transformation \\
\hline Airframe Hours & Log(hours) & Log transformation \\
\hline \multirow{2}{*}{ Fuel System } & 0 & Carburetor \\
\hline & 1 & Fuel injected \\
\hline \multirow{3}{*}{ Light Condition } & 0 & Daylight \\
\hline & 1 & Dark \\
\hline & 2 & Dusk \\
\hline \multirow{4}{*}{ Season of the Year } & 0 & $\begin{array}{l}\text { Winter (December to } \\
\text { February) }\end{array}$ \\
\hline & 1 & Spring (March to May) \\
\hline & 2 & Summer (June to August) \\
\hline & 3 & $\begin{array}{l}\text { Fall (September to } \\
\text { November) }\end{array}$ \\
\hline
\end{tabular}

Table 5 presents the parameter estimates from the logistic regression model. Wald Statistics is used to test the statistical significance of each coefficient in the 
model. Odds ratios are the probability of occurring over the probability of not occurring for an event. The regression results indicate that the model is able to correctly classify $70.21 \%$ of the cases into aircraft issue caused or none aircraft issue caused accident with statistical reliability at $10 \%$ significance level (p-value of Chi-square test: 0.078 ). In addition, five coefficients are statistically significant at 5\% level: pilot certificate (ATP/commercial, CFI/commercial, vs. commercial only), instrument rating (instrument rated vs. not instrument rated), type of engine (reciprocating engine, turbo-prop engine, vs. turbo-fan engine), maximum gross weight, and fuel system (carburetor vs. fuel injected) were identified as risk factors for Part 135 aircraft issue caused accidents.

Table 5

Logistic Regression Parameter Estimates and Odd Ratios

\begin{tabular}{|c|c|c|c|c|c|}
\hline \multirow{3}{*}{ Variable } & \multirow{3}{*}{ Coefficient } & \multirow{3}{*}{ Wald Sig. } & \multirow{3}{*}{ Odds ratio } & \multirow{2}{*}{\multicolumn{2}{|c|}{$95 \% C I$ in }} \\
\hline & & & & & \\
\hline & & & & Lower & Upper \\
\hline $\begin{array}{l}\text { Hours Flown with } \\
\text { the Same Model }\end{array}$ & 0.000 & 0.198 & 1.012 & 0.741 & 1.409 \\
\hline Total Hours Flown & 0.000 & 0.335 & 0.988 & 0.812 & 1.221 \\
\hline Pilot Certificate & 0.147 & $0.010 *$ & 1.158 & 0.415 & 3.232 \\
\hline Instrument Rating & -1.894 & $0.046^{*}$ & 0.150 & 0.023 & 0.964 \\
\hline Weather Condition & 0.503 & 0.182 & 1.653 & 0.790 & 3.462 \\
\hline Number of Engines & -0.233 & 0.477 & 0.792 & 0.417 & 1.506 \\
\hline Type of Engine & 0.012 & $0.028 *$ & 0.229 & 0.062 & 0.852 \\
\hline $\begin{array}{l}\text { Maximum Gross } \\
\text { Weight }\end{array}$ & 0.095 & $0.002 *$ & 1.102 & 0.821 & 1.479 \\
\hline Airframe Hours & 0.592 & 0.153 & 1.008 & 0.698 & 1.368 \\
\hline Fuel System & 0.501 & $0.006^{*}$ & 0.606 & 0.197 & 1.866 \\
\hline Light Condition & -0.379 & 0.178 & 0.684 & 0.384 & 1.189 \\
\hline Season of the Year & -0.169 & 0.202 & 0.845 & 0.652 & 1.095 \\
\hline Constant & 3.092 & $0.021^{*}$ & 22.021 & & \\
\hline \multicolumn{2}{|c|}{$\begin{array}{l}\text { Cox \& Snell R-sq. }=0.141 \\
\text { Overall percentage of correct }\end{array}$} & tion = & & \multicolumn{2}{|c|}{ Nagelkerke R-sq. $=0.194$} \\
\hline
\end{tabular}

\section{Conclusion}

Part 135 aircraft are operating with relatively less stringent safety program criteria compared to Part 121 operations. The NTSB identified the safety of Part 135 aircraft flight operations as one of the most wanted transportation safety improvements and recommended implementation of flight data monitoring (FDM) programs to mitigate the risk of Part 135 operations. The FDM programs attempt to mitigate flight risk by routinely collecting and analyzing aircraft operational data 
to detect and predict unsafe situations before aircraft mishap happens, but it is expensive. A better understanding of the aircraft issues that caused accidents in Part 135 flight operations is to facilitate the development of more practical and effective FDM programs.

With the motivation as aforementioned, this study, focusing on the aircraft issue caused accidents of Part 135 operations recorded in the NTSB aircraft accident database, analyzed the most common aircraft issues and risk factors that caused or may contribute to accidents involving Part 135 operations. The following findings and recommendations are reflected from data analysis:

Descriptive analysis provides general knowledge of statistical characteristics of Part 135 aircraft issue caused accidents through 2008 to 2018. It is similar to the statistical features of overall aircraft accidents per the flight phase of flight and type of aircraft: the approach/landing and takeoff/initial climb phases of flight show higher percentage of Part 135 aircraft issue caused accidents, and single piston engine and twin piston engine aircraft share most Part 135 aircraft issue accidents. Meanwhile, pilots involved in aircraft issue caused accidents were likely experienced pilots as per the total flight hours and the hours flown on the same aircraft model. In addition, over half of Part 135 aircraft issue caused accidents happened under the environment of VMC and good light condition. The temporal trend analysis does not provide enough evidence that Part 135 aircraft issue caused accidents increased or decreased during the studied period.

Based on the NTSB categorization of aircraft accident causes and investigation results, a list of common aircraft issues was identified. Aircraft operation capability exceedance is believed the most common categorical aircraft issue caused accidents followed by aircraft systems and aircraft power plant. More specifically, directional control not attained/maintained, landing gear failure, and reciprocating engine section failures were identified as three most common subcategorical aircraft issues. Identification of common aircraft issues is expected to help FDM better scope aircraft parameters to be monitored. Findings of this study suggest that aircraft data related to aircraft directional control, landing gear systems, and reciprocating engine should be more comprehensively monitored in FDM programs. In addition, the result of risk factor analysis shows that pilot experience by the type of certificate and instrument rating, type of engine, maximum gross weight of aircraft, and the fuel system could be risk factors contributing to aircraft issue caused accident. Pilots only owning commercial certificates without instrument rating are more likely to experience an aircraft issue caused accident with higher chance compared to pilots an ATP certificate and instrument rated. Heavy aircraft with reciprocating carburetor fueling engine(s) might be more vulnerable to aircraft issue caused accidents in comparison with lighter turbo fuel injected engine aircraft. 
In conclusion, this study is expected to provide insight for the development of more practical and effective FDM programs for Part 135 operators by focusing on Part 135 aircraft issue caused accidents. However, this is an initial attempt to analyze aircraft accident data for the purpose of facilitating better development and implementation of FDM programs. Further study is necessary to validate the findings by incorporating additional data and analytical techniques. 


\section{References}

Agresti, A. (2012). Categorical data analysis (3rd ed). New York, NY: Wiley. Augiar, M., Stolzer, A., \& Boyd, D. D. (2017). Rates and causes of accidents for general aviation aircraft operating in a mountainous and high elevation terrain environment. Accident Analysis and Prevention, 107, 195-201.

Bazargan, M., \& Guzhva, V. S. (2011). Impact of gender, age and experience of pilots on general aviation accidents. Accident Analysis and Prevention, 43, 962-970.

Bazargan, M., \& Guzhva, V. S. (2007). Factors contributing to fatalities in general aviation accidents. World Review of Intermodal Transportation Research, 1(2), 170-182.

Boyd, D. D. (2015). Causes and risk factors for fatal accidents in non-commercial twin engine piston general aviation aircraft. Accident Analysis and Prevention, 77, 113-119.

Boyd, D. D., \& Macchiarella, N. D. (2016). Occupant injury severity and accident causes in helicopter emergency medical services (1983-2014). Aerospace Medicine and Human Performance, 87(1), 26-31.

Burgess, S., Boyd, S., \& Boyd, D. (2018). Fatal general aviation accidents in furtherance of business: Rates, risk factors, and accident causes. Journal of Aviation Technology and Engineering, 8(1), 11-19.

Campbell, N. (2007). The evolution of flight data analysis. Proceeding from Australian Society of Air Safety Investigators conference, 2007.

Federal Aviation Administration. (2004). Flight operational quality assurance (AC No. 120-82). Retrieved from http://www.airweb.faa.gov/Regulatory and_Guidance_Library/rgAdvisoryCircular.nsf/0/40c02fc39c1577b68625 6e8a005afb0a/\$FILE/AC120-82.pdf

Federal Aviation Administration. (2016). Study of operators regulated under Part 135. Retrieved from https://www.faa.gov/about/office_org/headquarters_ offices/avs/offices/afx/afs/afs200/afs250/

Federal Aviation Administration. (2019a). FOQA participants as of 08/20/2019. Retrieved from https://www.faa.gov/about/office_org/headquarters_ officesavs/offices/afx/afs/afs200/afs280/descriptions/media/FOQA_Partici pants.pdf

Federal Aviation Administration. (2019b). General aviation and part 135 activity surveys - 2017 historical general aviation and air taxi measures. Retrieved from https://www.faa.gov/data_research/aviation_data_ statistics/general_aviation/CY2017/

Federal Aviation Administration. (2019c). Part 135 aircraft listing from operations specification. Retrieved from https://www.faa.gov/about/ office_org/headquarters_offices/avs/offices/afx/afs/afs200/afs260/media/1 35aircraft.xlsx 
Federal Aviation Administration (2020). Air operator information updated by February 3, 2020. Retrieved from https://av-info.faa.gov/dd_sublevel.asp? Folder $=\% 5$ CAirOperators

International Civil Aviation Organization. (2016). Annex 13 to the convention on international civil aviation, aircraft accident and incident investigation (11th ed.). Montreal, Canada: Author.

Khatwa, R., \& Roelen, A.L.C. (1997). Controlled flight into terrain (CFIT) accidents of air taxi, regional and major operators. National Aerospace Laboratory NLR TP 97270, Amsterdam, the Netherlands.

Li, G., \& Baker, S. P. (2007). Crash risk in general aviation. Journal of the American Medical Association, 297(14), 1596-1598.

Li, G., Baker, S. P., Grabowski, J. G., \& Rebok, G. W. (2001). Factors associated with pilot error in aviation crashes. Aviation Space and Environment Medicine, 72(1), 52-58.

Li, G., \& Baker, S. P. (1999). Correlates of pilot fatality in general aviation crashes. Aviation Space and Environment Medicine, 70(4), 305-309.

National Transportation Safety Board. (2019a). Aviation accident database \& synopses. Retrieved from https://www.ntsb.gov/_layouts/ntsb.aviation/ index.aspx

National Transportation Safety Board. (2019b). 2019-2020 NTSB most wanted list of transportation safety improvements. Retrieved from https://www.ntsb.gov/safety/mwl/Pages/mwlfs-19-20/mwl3-fsa.aspx

Operating requirements: Commuter and on-demand operations and rules governing persons on board such aircraft - Applicability, 14 Code of Federal Regulations, Part 135.1 (2019).

Reason, J. (1990). Human error. New York, NY: Cambridge University.

Rebok, G. W., Qiang, Y., Baker, S. P., \& Li, G. (2009). Pilot age and error in air taxi crashes. Aviation, Space, and Environment Medicine, 80(7), 647-651.

Shao, B. S., Guindani, M., \& Boyd D. D. (2014). Causes of fatal accidents for instrument-certified and non-certified private pilots. Accident Analysis and Prevention, 72(2014), 370-375.

Tabachnick, B. C., \& Fidell, L. S. (1996). Using multivariate statistics. New York, NY: HarperCollins. 